\title{
Educação e trabalho: formação profissional para jovens com deficiência intelectual na escola especial
}

\author{
Valéria Becher Trentin* \\ Tânia Regina Raitz**
}

\section{Resumo}

O trabalho é elemento central no processo de transição para a vida adulta do jovem com deficiência intelectual. No entanto para que estes jovens ofereçam qualidade no desempenho de uma função, faz-se necessária uma formação profissional adequada. Neste sentido, o presente artigo teve como objetivo analisar as contribuiçóes da formação profissional ofertada pela escola especial para a inclusão do jovem com deficiência intelectual (DI) no mercado de trabalho. De abordagem qualitativa se utilizou como instrumento de coleta de dados a entrevista semiestruturada e, como sujeitos, 4 (quatro) profissionais que atuam em oficinas de formação profissional em uma Escola Especial, situada no Estado de Santa Catarina. Mediante os resultados concluiu-se que há necessidade de novos estudos, em especial no que diz respeito à formação profissional para jovens com DI, na relação que se estabelece entre educação e trabalho. Igualmente, são necessários estudos que discutam práticas a serem desenvolvidas na formação profissional, dadas as mudanças no mundo do trabalho e no mundo desses jovens que almejam tanto estar inseridos numa sociedade inclusiva.

Palavras-chave: Educação; Trabalho; Formação profissional; Jovem com deficiência intelectual.

\footnotetext{
* Mestre em Educação e Doutoranda em Educação pela Universidade do Vale do itajaí (UNIVALI), Itajaí, Santa Catarina, Brasil.

** Doutora em Educação pela Universidade Federal do Rio Grande do Sul. Porto Alegre, Rio Grande do Sul, Brasil.
} 


\section{Education and work: professional training for young people with intellectual in special school}

\section{Abstratc}

Work is a central element in the process of transition to adulthood of young people with intellectual disabilities. However, for these young people to provide quality in the performance of a job, adequate vocational training is required. In this sense, the present article had as objective to analyze the contributions of the professional training offered by the special school for the inclusion of young people with intellectual disability (ID) in the labor market. From a qualitative approach, the semi-structured interview was used as a data collection instrument and, as subjects, 4 (four) professionals who work in professional training workshops at a Special School, located in the State of Santa Catarina. It was concluded that there is a need for further studies, especially in relation to vocational training for young people with ID, in the relationship between education and work. Likewise, studies are needed that discuss practices to be developed in vocational training, given the changes in the world of work and in the world of these young people who so desire to be inserted in an inclusive society.

Keywords: Education; Work; Professional qualification; Young intellectual. disabilitie.

\section{Introdução}

A formação profissional ${ }^{1}$ ganhou importância devido a crise do paradigma fordista-taylorista ${ }^{2}$. Para iniciar discussóes sobre o tema, buscou-se o conceito de formação, em Manfredi (2007, p. 11), o qual evidencia que esta, "expressa diferentes visôes de mundo, de sociedade, de desenvolvimento socioeconômico, e que serve como matrizes para projetos diferentes de educação [diga-se formação] profissional e de políticas públicas de qualificação".

No que tange à qualificação profissional, o autor ainda destaca que há diferentes concepçôes, e que estas "são construídas mantendo vínculos com as noçốes de trabalho, produção social, desenvolvimento socioeconômico (com projetos e proposições de desenvolvimento), educação e formação profissional." (MANFREDI 2007, p. 11). Sobre a educação e formação profissional, Pochmann (2001) menciona que existe uma inadequação desta em relação ao "aparelho produtivo", pois as circunstâncias em que se inserem a educação profissional e a qualificação, retratam um momento de transição para a nova economia produtiva que impóe a formação continuada. $\mathrm{O}$ mesmo autor ainda menciona que uma renovação da formação profissional dos trabalhadores deveria integrá-la aos desafios recentes da economia brasileira, envolvendo os setores governamental, empresarial e de trabalhadores. Essa renovação visa desenhar uma nova formação que culmine em melhor transição do sistema educacional para o setor produtivo. (POCHMANN, 2001). 
Sobre a transição do sistema educacional para o setor produtivo, Franzoi (2006) menciona ser essencial ter em mente a interdependência que ocorre entre a educação e a empresa. Entende-se que a inserçáo profissional acontece com a interdependência e a autonomia de três esferas:

(a) a preparação, que remete aos conhecimentos adquiridos nos órgãos de formaçáo com vistas a capacitar os indivíduos para um lugar no mercado de trabalho; b) a transiçáo, que remete à busca de emprego e a um conjunto de mecanismos que se situam na interface dos órgãos de formação e de trabalho; c) a integração profissional propriamente dita. (FRANZOI, 2006, p. 164)

O processo de transição para o mercado de trabalho, mencionado por Franzoi (2006), pode configurar-se por um período ou ser permanente, por necessitar de uma integração de construção social e até mesmo de aceitação do novo trabalhador. Da mesma forma, a transiçáo para o primeiro emprego pode significar a continuidade dos estudos ou simplesmente representar o fim de um processo de busca e a ocorrência da inserção profissional. Trottier (1999, p. 152) assim apresenta o processo para a obtenção do emprego formal:

A preparação profissional remete aos conhecimentos transmitidos aos jovens nos órgãos de formação em vista de habilitá-los a conseguir um lugar no mercado de trabalho. Esses conhecimentos transformam-se em qualificaçóes [...] A transição profissional é caracterizada pela procura de emprego e por um conjunto de mecanismos que se situam na interface da escola e do trabalho. [...] Em seguida vem a fase da integraçáo profissional propriamente dita, ou por uma relativa estabilidade de emprego, ou por situaçóes de espera em relaçáo ao acesso a um emprego, ou por situaçóes de marginalização, ou de exclusão do mercado de trabalho. (TROTTIER, 1999, p. 152)

Compreende-se que o processo descrito por Trottier dependerá da capacidade integrativa da sociedade, capaz ou não de dar espaço a novos trabalhadores, numa relação direta com a divisão do trabalho. $\mathrm{O}$ percurso de inserção no mercado de trabalho pode ser entendido como um processo de socialização profissional, que remete aos conhecimentos adquiridos, às habilidades, às normas e aos valores próprios de uma ocupação, resultante da identidade social.

A partir do contexto exposto, realizou-se a presente pesquisa, com o objetivo de analisar as contribuiçôes da formação profissional ofertada pela escola especial para a inclusão do jovem com DI no mercado de trabalho.

Para tanto, o presente artigo encontra-se dividido em quatro seçóes principais. Na primeira seção, apresenta-se a metodologia da pesquisa. $\mathrm{Na}$ segunda seção apresenta-se um diálogo entre a temática Jovem com DI, Educação e Trabalho. Na terceira seção apresenta-se por meio dos dizeres dos sujeitos a formaçáo profissional ofertada aos jovens com DI na Escola Especial e na quarta seçấo as consideraçóes finais. 


\title{
Metodologia: caminhos trilhados e procedimentos da pesquisa
}

Com a intenção de analisar as contribuiçôes da formação profissional ofertada pela escola especial para a inclusão do jovem com DI no mercado de trabalho, foi realizada pesquisa de abordagem qualitativa, com 4 (quatro) profissionais que atuam diretamente nas Oficinas de Formação para o Trabalho em uma Escola Especial localizada em um município do Estado de SC.

Como instrumento de coleta de dados utilizou-se a entrevista semiestruturada que, segundo Bauer e Gaskell (2002, p. 64) precisa pressupor que o mundo social não é um dado natural, sem problemas, pois "Ele é ativamente constituído por pessoas em suas vidas cotidianas, mas não sob condiçôes que elas mesmas estabeleceram", como também se assume "que essas construçôes constituem a realidade essencial das pessoas, e de seu mundo vivencial." Esses mesmos autores elucidam que,

\begin{abstract}
O emprego da entrevista qualitativa para mapear e compreender o mundo da vida dos respondentes é o ponto de entrada para os esquemas interpretativos e compreender as narrativas dos atores, em termos mais conceptuais e abstratos, pois fornece os dados básicos para o desenvolvimento e a compreensão das relaçóes entre os atores sociais e sua situação (BAUER e GASKELL, 2002, p. 64).
\end{abstract}

As entrevistas com os 4 (quatro) profissionais foram realizadas no espaço escolar pesquisado. Utilizou-se com o consentimento dos entrevistados o gravador. Após a realização das entrevistas, fez-se a transcrição, com o cuidado de manter fidelidade a todos os dizeres e expressões. As transcriçôes, por sua vez, foram analisadas por meio da análise de conteúdo conforme estabelece Franco (2005), em que as informaçôes devem ser trazidas em seus diversos significados.

\section{Jovem com defeciência intelectual: educação e trabalho}

O jovem com deficiência, assim como qualquer jovem, almeja um lugar na sociedade, deseja obter bens de consumo, trabalhar e também dar continuidade aos estudos. Esses sonhos e desejos são inerentes ao jovem, independente de possuir ou não uma deficiência. É na busca pela realizaçáo dos sonhos e desejos, que surge a escola. Sobre este aspecto Branco (2005), destaca os vínculos existentes entre a educação e o trabalho. O autor menciona que entre os jovens, constata-se "que três entre cada quatro jovens estão atribuindo ao binômio, educação e trabalho o significado de assunto que mais lhe interessa”. (BRANCO, 2005, p.140). É nesse binômio que os jovens depositam suas expectativas sempre relacionadas a um futuro imediato, mesmo que, muitas vezes, tais expectativas não sejam animadoras, sem negar que é mais difícil para os jovens com deficiência.

No entanto, mediante este binômio há de se considerar os resultados de pesquisas que trazem à tona as dificuldades que os jovens enfrentam na busca por oportunidades de trabalho no cenário social contemporâneo. Pais (2005), ao comen- 
tar sobre a condição de vida dos jovens menos favorecidos, seja em função da situação econômica, seja pela deficiência, caracteriza o mercado de trabalho como restrito, exigente e, por isso, excludente.

Em se tratando da pessoa com deficiência, ressalta-se que a educação exerce um papel fundamental em sua inserção e permanência no mercado de trabalho. Porém, nessa relação educação/trabalho, torna-se necessário um planejamento de transição para a vida pós-escolar, a qual envolva a escola, a família e o próprio jovem. A respeito da preparação de jovens com DI para o período após a escola, Araújo (2008) frisa que deve incluir o planejamento para o trabalho e para a vida na comunidade de modo geral. A autora também menciona que, nos Estados Unidos, existe um documento legal denominado Ato de Educação para Indivíduos com Deficiências, que obriga as escolas a prepararem um planejamento para essa transição. De acordo com este documento,

O plano de transição deve focalizar a trajetória escolar das pessoas com deficiências e oferecer detalhes sobre como a instrução e as expectativas na comunidade possibilitaráo preparar tais pessoas para a vida adulta e para sua empregabilidade no ambiente de trabalho. Nesse sentido, as escolas têm um papel decisivo no planejamento da transiçáo das pessoas com deficiência mental (ARAÚJO, 2008, p.76-77).

Araújo (2008) também elucida que o plano de transição se torna possível por meio da elaboraçáo de um currículo funcional ${ }^{3}$ com atividades selecionadas e desenvolvidas que incluam habilidades importantes para o futuro desempenho na sociedade e no trabalho. De modo geral, trata-se da estruturação de um ensino que visa oferecer oportunidades para que o jovem aprenda habilidades importantes, para torná-lo independente em diversas áreas da vida. Assim compreende-se que o êxito do processo de transição da escola para o trabalho, sob essa perspectiva, está relacionado aos aspectos do plano de transição individual de cada jovem.

Mediante a experiência vivenciada nos Estados Unidos, pondera-se que, no Brasil, o desafio da profissionalizaçáo de pessoas com DI suscita investigaçáo sobre caminhos possíveis que favoreçam, no contexto educacional, o desvelamento das problemáticas inerentes a esse processo. Sobre este aspecto, a Declaração de Salamanca (1994, p. 80), anuncia que,

Jovens com necessidades educacionais especiais deveriam ser auxiliados no sentido de uma transição efetiva da escola para o trabalho. Escolas deveriam auxiliá-los a se tornarem economicamente ativos e provê-los com as habilidades necessárias ao cotidiano da vida, oferecendo treinamento em habilidades que correspondam às demandas sociais, de comunicação e às expectativas da vida adulta [...]. O currículo para estudantes mais maduros e com necessidades educacionais deveria incluir programas específicos de transição, treinamento vocacional que os prepare a funcionar, independentemente enquanto membros contribuintes em suas 
comunidades e após o término da escolarização. Tais atividades deveriam ser levadas a cabo como o envolvimento ativo de aconselhadores vocacionais, oficinas de trabalho [...] (ONU, 1994, p.80).

Entre os documentos legais nacionais que revelam a preocupação com a inserção da pessoa com deficiência no mercado de trabalho, encontra-se a Constituição da República Federativa do Brasil, de 1998, que assegura o direito à educação profissional visando integrar socialmente o adolescente e o adulto com deficiência (BRASIL, 1998). No que se refere à educação profissional, tem-se a Lei de Diretrizes e Bases da Educação Nacional (Lei Federal no 9394/96) que, em seu inciso IV, assegura:

Educação Especial para o trabalho, visando sua efetiva integração na vida em sociedade, inclusive condiçóes adequadas para os que não revelarem capacidade de inserção no trabalho competitivo, mediante articulação com os órgãos oficiais afins, bem como para aqueles que apresentam uma habilidade superior nas áreas artística, intelectual ou psicomotora (BRASIL, 1996)

Outro documento a ser citado é o Decreto no 3.298, de 20 de dezembro de 1999 (BRASIL, 1999), que dispôe sobre a Política Nacional para a Integração da Pessoa Portadora de Deficiência. Em seu artigo $28, \S 1^{\circ}$, determina que a educação profissional da pessoa com deficiência deve ser oferecida nos níveis básico, técnico e tecnológico, em escolas regulares, em instituiçóes especializadas e no ambiente de trabalho. Do mesmo modo, a Lei Federal no 8.213, de 24 de julho de1991 (BRASIL, 1991), conhecida como Lei de Cotas, prevê a contrataçáo de $2 \%$ a $5 \%$ de pessoas com deficiência em empresas com mais de 100 funcionários e proíbe qualquer ato discriminatório em relação ao salário ou critério de admissão associado à deficiência da pessoa.

No entanto, apesar do aparato legal, está distante a viabilização do acesso e permanência de pessoas com deficiência no mercado de trabalho. Niskier (2006) menciona que o Ministério do Trabalho e do Emprego publicou, em 2006, dados com um considerável aumento no número de contrataçáo de pessoas com deficiência no mercado de trabalho, ou seja, um percentual expressivo de $56 \%$ de pessoas com deficiência estariam inseridas no mercado de trabalho, resultando num número de 19.978 sujeitos. Esse fato se justifica em função da fiscalizaçẫo do Ministério do Trabalho e Emprego, em virtude da Lei de Inclusão Social em vigência desde o ano de 2004. Contudo, nos anos subsequentes à implantação da Lei, ocorreu um significativo decréscimo desse percentual, passando para 4.151 o número de pessoas com deficiências que ocupam funçôes nos mais variados segmentos empresariais. Ainda de acordo com Niskier (2006), esse decréscimo nas contrataçóes decorre da ausência de qualificações e de formação educacional requeridas pelo mercado de trabalho, o que dificulta e até mesmo impede a inserção no mercado de trabalho, tanto de pessoas sem deficiência, quanto de pessoas com deficiência.

Ao encontro das ideias de Niskier (2006), destaca-se Araújo (2008) para quem as pessoas com deficiência têm sido excluídas do mercado de trabalho por vários motivos: falta de qualificação para o trabalho e baixa escolaridade, bem como apoio insuficiente das famílias. Além das razóes citadas, encontram-se o preconceito e as 
barreiras atitudinais que dificultam ainda mais esse processo. Ainda a respeito da relação entre Educação e Trabalho no que se tange às Pessoas com Deficiências (PCDs), é possível mencionar os dados fornecidos pela Relação Anual de Informaçôes Sociais (RAIS):

Em 2015, verificou-se um aumento de 5,75 \% no número de pessoas declaradas como deficientes-PCD, em relaçáo ao ano de 2014. Segundo os dados da Relaçáo Anual de Informaçóes Sociais (Rais) 2015, divulgada pelo Ministério do Trabalho, 403,2 mil pessoas com deficiência atuam formalmente no mercado de trabalho, correspondendo a um percentual de $0,84 \%$ do total dos vínculos empregatícios. Os dados da RAIS por Grau de Instrução e Tipo de Deficiência revelam que o Ensino Médio Completo concentra o maior número de vínculos empregatícios de todas as modalidades, à semelhança do total dos vínculos. Entre os cinco tipos de deficiência, o menor número de vínculos empregatícios ocorre na categoria dos Analfabetos. (MINISTÉRIO DO TRABALHO E EMPREGO, 2015).

Em síntese, considera-se pertinente salientar a importância da educação na vida das pessoas com deficiência, pois esta não cumpre apenas o ofício de preparar as pessoas com limitaçóes para se adaptarem à sociedade e ao mundo do trabalho. $\mathrm{Na}$ medida do possível, a educação as prepara para que possam compreender a realidade que as cerca em sua complexidade e historicidade, atuando em prol de formas mais humanizadas de existência social.

\section{Formação profissional para jovens com deficiência intelectual na educação especial}

A Escola Especial pesquisada está localizada em um município do Estado de SC, e atualmente, oferece turmas de Educação Infantil, Serviço de Atendimento Educacional Especializado $(\mathrm{SAEDE})^{4}$ e Oficinas de Formaçáo Profissional. As oficinas são o objeto de análise da pesquisa ora apresentada

Segundo o Coordenador Pedagógico, as oficinas funcionam no período matutino e vespertino, atendendo, atualmente, 100 (cem) jovens, com idade acima de 15 (quinze) anos. Ao referir-se às oficinas o coordenador pedagógico, destaca que estas são organizadas em salas ambiente para o desenvolvimento de atividades artesanais.

As oficinas são variadas[...] através das oficinas os alunos desenvolvem qualidades que todo trabalhador deveria ter: pontualidade, assiduidade, persistência na execução de um serviço, higiene corporal e várias qualidades que são exigidas no mercado de trabalho. (COORDENADOR PEDAGÓGICO)

Os dizeres do coordenador elucidam que as oficinas contribuem para preparar e não profissionalizar as pessoas com DI, porque visam à formação de hábitos e comportamentos sociais considerados adequados aos trabalhadores. Diante do depoimento do entrevistado, cabe diferenciar profissionalização de preparaçáo profissional. 
A profissionalização "refere"-se a estar apto para exercer uma profissão, atividade ou ocupação especializada, da qual se obtém os meios de subsistência, enquanto "preparar para o trabalho significa preparar para uma vida produtiva, através da prática de atividades que desenvolvam a capacidade laborativa" (VALLE, 2004, p. 27). Em outras palavras, em consonância com o mesmo autor,

[...] há uma clara distinção entre ambos. O primeiro termo referese à educação de uma profissão específica e todas as questóes dela decorrentes, com a habilitação profissional. O outro diz respeito à preparaçáo para o trabalho, qualquer trabalho, estando suas açōes mais voltadas para a formação de hábitos e atitudes inerentes ao trabalhador. (VALLE, 2004, p. 27)

Assim entende-se que as oficinas não profissionalizam os jovens com DI, mas sim desenvolvem rotinas na escola que visam formar um comportamento "adequado", com respeito a normas e regras sociais.

Sobre as oficinas o Professor 1 menciona que,

As nossas oficinas são bem variadas. Nós temos a oficina da costura, reciclagem [...] marcenaria. [...] $\mathrm{Na}$ oficina de pintura eles pegam as caixinhas e vão pintar. Ou é pano de prato, ponto cruz, crochê, tricô, bordados em geral [...]. Temos também a oficina de reciclagem que trabalha com papel.

Diante a função das oficinas destacada pelo professor 1, Tanaka e Manzini (2005) tecem críticas, ao mencionarem que estas pouco contribuem para qualificar as pessoas com deficiência. Segundo os autores, as referidas oficinas adotam práticas desvinculadas do mercado competitivo, reproduzindo os mesmos processos utilizados no processo histórico da educação especial. Ao encontro dos autores, Silva et al (2001), destacam que na capacitação profissional torna-se necessário romper com práticas assistencialistas que limitam o trabalho, oferecendo à pessoa com deficiência possibilidades de mediar suas relaçóes com o mundo. Relaçóes estas, que visam autonomia e a utilização do trabalho como meio de inclusão social.

Ao encontro do mencionado pelo Professor 1, o Professor 2 assim explicou:

$\mathrm{Na}$ oficina de reciclagem de papel a gente trabalha por encomendas. Cada um faz o mesmo processo na confecçáo. Depois eles vendem os produtos que são confeccionados. (PROFESSOR 2)

$\mathrm{Na}$ oficina de reciclagem de papel, conforme o Professor 2, o trabalho é desenvolvido por meio de metas produtivas, pois os produtos sáo fabricados para a venda em grandes quantidades, sendo o trabalho realizado do começo ao fim da produçáo. Mediante o anunciado, compreende-se que a autonomia e a produçáo criativa não fazem parte dos objetivos dessa oficina. Os alunos ficam segregados à instituiçáo, desenvolvendo práticas de trabalho fragmentadas, nos moldes taylorista-fordista, o que torna esses jovens estudantes subordinados à escola e a ela dependentes. Sobre essa segregação Valle (2004, p.22) anuncia que, "no Brasil, a grande maioria dos programas de educação para o trabalho para pessoas com necessidades especiais ocorrem, quase que exclusivamente, em ambientes segregados, nas oficinas pedagógicas [...]" (VALLE, 2004, p. 22) 
Contrário o evidenciado na Escola Especial, Cerqueira (2004) destaca a necessidade de ser proporcionado ao jovem um ambiente de aprendizagem para o trabalho em contexto real. Ambiente este, pautado no currículo funcional, o qual integre a aprendizagem e o suporte para o trabalho, pois preparar o jovem para o trabalho envolve propiciar experiências que possibilitem suas escolhas e o confrontamento de suas expectativas com a realidade.

Outro aspecto a ser destacado, na Escola Especial, foi à atribuição a um grupo de profissionais a tarefa de intermediar a inclusão dos jovens no mercado de trabalho. Os profissionais entram em contato com as empresas e buscam vagas de emprego para os jovens com DI. Igualmente os mesmos profissionais, prestam assistência aos jovens e as suas famílias. Fornecem orientação sobre a documentação necessária para o ingresso profissional, como, por exemplo, a carteira de trabalho, e fazem a assessoria na contratação e o acompanhamento funcional. Entre os profissionais desse grupo, encontra-se a Psicóloga, que assim se expressou:

A psicóloga que faz parte da equipe acompanha este aluno na entrevista e, depois, na contratação. A equipe acompanha a inclusão conforme a necessidade, visitando a empresa vendo como que está o desenvolvimento do jovem no trabalho. (PSICÓLOGA)

Tem-se o entendimento de que o acompanhamento para a pessoa com deficiência, é uma das chaves pós-contratação que ajudaria na manutenção do emprego. Essa importância se dá devido ao vínculo que a escola tem com esse jovem, e ao conhecimento de suas limitaçóes e potencialidades. Sobre esse acompanhamento, Araújo (2008) destaca a importância da proposta de emprego apoiado, cujos objetivos são integrar no trabalho e na sociedade pessoas com diferentes graus de comprometimentos e propiciar um emprego efetivo e remunerado no mercado competitivo de trabalho, devendo ser exercido em ambientes naturais. As formas mais frequentes de desenvolvimento do emprego apoiado são a colocação individual e seletiva ${ }^{5}$.

No entanto cabe destacar que para além do acompanhamento, no processo de inclusão do jovem no mercado de trabalho, há que se considerar, uma capacitação profissional por meio de programas de educação para o trabalho a fim de que o treinamento seja adequado à sua condição para se promover a dignidade e a cidadania. (MIURA, et al. 2010).

Referente à inclusão do jovem com DI no mercado de trabalho, a Psicóloga ainda mencionou,

A equipe que acompanha a inclusão destes alunos é formada por Psicólogos, Terapeutas Ocupacionais, Fisioterapeutas, Fonoaudiólogos e Assistentes Sociais. (PSICÒLOGA)

Mediante o anunciado, compreende-se que a Escola Especial, visando à inserção profissional, aproxima vários profissionais nesse processo com o intuito de desenvolver um trabalho interdisciplinar. Segundo a psicóloga "são estes profissionais que realizam com os jovens que são encaminhados ao mercado de trabalho atividades em grupos, com projetos de habilidades sociais e atividades da vida diária. Também realizam um trabalho de orientação às famílias, de palestras e de acolhimento a elas.” 
Em relação a orientação às famílias, sobre a inclusão do jovem com deficiência no mercado de trabalho, a psicóloga aponta o Benefício de Prestação Continuada (BPC), mencionado na Lei Federal n. 8.742, de 7 de dezembro de 1993 (BRASIL, 1993) como um entrave no processo. Esse benefício é caracterizado como uma aposentadoria, com valor de um salário mínimo, concedida à pessoa com deficiência pelo Instituto Nacional do Seguro Social (INSS), o qual atesta sua incapacidade para o trabalho. O jovem com o benefício geralmente não é inserido no mercado de trabalho. De acordo com a Psicóloga entrevistada,

O benefício quando a família consegue, têm medo de trocar o certo pelo duvidoso. Ás vezes o jovem náo vai para o mercado de trabalho por medo que a família tem de perder. A gente deixa bem à vontade a família. (PSICÓLOGA)

O depoimento da Psicóloga aponta para a necessidade de considerar o conflito e o temor da família da pessoa com deficiência em relaçáo a dispensar o benefício, tendo em vista seu auxílio na manutenção das despesas pessoais e na renda familiar. A inserção no mercado de trabalho associado à perda do benefício gera tensão nos responsáveis pelas pessoas com deficiência e interfere na vontade dos próprios jovens. Portanto, não é possível desconsiderar esse conflito quando se trata de discutir a relação "jovem com deficiência, educação e trabalho".

É relevante destacar, entretanto, que, em agosto de 2011, foi sancionado o projeto de conversão da Medida Provisória 529, na Lei 12.470/11 (BRASIL, 2011), a partir da qual a pessoa com deficiência, mesmo recebendo o Benefício de Prestação Continuada (BPC) poderá ser contratada como aprendiz e acumular o salário com o beneficio. Caso seja efetivada em uma empresa, o benefício será suspenso e não mais cancelado, podendo ser reativado em caso de demissão ou saída do emprego.

Mediante a breve exposição sobre a formação do jovem com DI na Escola Especial, vale destacar que na inclusão social e econômica da pessoa com deficiência no mercado de trabalho, vários agentes e instituiçóes têm papel fundamental: o Estado, não somente via política de Cotas, mas por incentivos e fiscalização; as famílias que, aos poucos, passam a entender que esses sujeitos não precisam ficar segregados em seus domicílios e à escola especial e principalmente a sociedade, que precisa conhecer o potencial desses jovens. Considera-se, ainda, que a sociedade e o trabalho do século XXI necessitam de pesquisas que impulsionem mudanças para a construção de alternativas econômicas, políticas e sociais para esses novos trabalhadores.

\section{Considerações finais}

A análise sobre a formação profissional para jovens com DI na relação educação/trabalho possibilitou um olhar mais aprofundado acerca dos desafios e obstáculos frente à inclusão destes, no mercado de trabalho. Os dizeres dos entrevistados elucidaram que as oficinas profissionalizantes da Escola Especial investigada têm privilegiado as atividades manuais, artesanais e as práticas comportamentais, pretendendo desenvolver habilidades para o mercado de trabalho. Mediante a prática da escola, 
percebe-se que as oficinas representam, para os jovens com deficiência, um espaço de acolhimento e de respeito e não uma possibilidade de integração efetiva mediante processos de qualificação para o trabalho.

Da mesma forma, os sujeitos entrevistados demonstraram, por meio de seus dizeres, que a formação profissional para a pessoa com DI não atende às necessidades e expectativas do mercado de trabalho, o que exige grandes discussões para além da escola. No sentido apontado, desvelam-se pontos cruciais que merecem ser analisados para inclusão na proposta das oficinas de profissionalização. Entre eles, pontuam-se:

-Trabalho colaborativo com a família dos jovens envolvendo atualizaçóes sobre a legislação, principalmente no que se refere às mudanças no Benefício de Prestação Continuada (BPC).

-Realização de um trabalho de autogestão com os jovens que os incentive a fazer escolhas, buscando valer suas vontades e necessidades.

- Formação com metodologias de ensino adequadas para desenvolver as possibilidades da pessoa com DI e os anseios do público jovem, com estágios na comunidade e em empresas locais.

Compreende-se que os aspectos pontuados como necessários para dinamização das oficinas são indicativos de novas propostas para ressignificar a Escola Especial. Frente a pesquisa realizada, concluiu-se que há necessidade de novos estudos, em especial no que diz respeito à formação profissional para jovens com DI, na relação que se estabelece entre educaçáo e trabalho. Igualmente, são necessários estudos que discutam práticas a serem desenvolvidas na formação profissional, dadas as mudanças no mundo do trabalho e no mundo desses jovens que almejam tanto estar inseridos numa sociedade inclusiva.

\section{Referências}

ARAÚJO, E. A. C. Deficiência Mental, suporte comunitário e transição para o trabalho. Araraquara, SP. Brasília, DF: CAPES PRODOC, 2008.

BAUER, M. W.; GASKELL, G. Pesquisa qualitativa com texto, imagem e som. Rio de Janeiro: Vozes, 2002.

BRANCO, P. P. M. Juventude e trabalho: desafios e perspectivas para as políticas públicas. In: ABRAMO, H.; BRANCO, P. P. M. (org.). Retratos da juventude brasileira: análises de uma pesquisa nacional. São Paulo: Fundação Perseu Abramo, 2005. p.129-148.

BRASIL. Constituição Federal do Brasil. 1988. Disponível em: http://www.senado.gov.br/atividade/const/ constituicao-federal.asp. Acesso em: 12 nov. 2014.

Lei Federal. No 8.213, de 1991. Dispóe sobre apoio às pessoas com deficiência e sua integração social, define outras providências. 1991 .

Lei n. 8.742, de 7 de dezembro de 1993. Dispóe sobre a organização da Assistência Social e dá outras providências. Disponível em: http://www.planalto.gov.br/ccivil_03/LEIS/L8742.htm. Acesso em: 20/12/2014.

Lei de Diretrizes e Bases da Educaçáo Nacional. Lei no 9.394, de 20 de dezembro de 1996. D.O.U. de dezembro de 1996. Florianópolis: Sindicato das Escolas Particulares de Santa Catarina, 1996.

Política Nacional para Integração da Pessoa Portadora de Deficiência. Decreto no 3.298, de 20 de dezembro de 1999. MEC/SEESP, 1999.

Lei no 12.470 de 31 de agosto de 2011. Dispõe sobre o Plano de Custeio da Previdência Social. 2011. 
Ministério do Trabalho. RAIS. Disponível em: http://www.brasil.gov.br/economia-e-emprego/2016/09/cresce -numero-de-pessoas-com-deficiencia-no-mercado-de-trabalho-formal. Acesso em : fev. 2016.

CERQUEIRA, J. B. Recursos didáticos na educaçáo especial. Instituto Benjamin Constant - Rede Saci, 2004.

CATTANI, A. D. (Org.) Dicionário crítico sobre trabalho e tecnologia. 4a ed. rev. ampl. Petrópolis: Vozes; Porto Alegre: UFRGS, 2002.

FRANCO, B. Análise de conteúdo. 2. ed. Brasília: Líber Livro, 2005.

FRANZOI, N. L. Inserção profissional. In: CATTANI, A. D.; HOLZMANN, L. Dicionário de trabalho e de tecnologia. Porto Alegre: UFRGS, 2006. p. 163-165.

LARANJEIRA, S. M. G. Fordismo e pós-fordismo. In: CATTANI, Antonio David; HOLZMANN, Lorena. Dicionário de trabalho e de tecnologia. Porto Alegre: UFRGS, 2006. p. 133 - 136.

MANFREDI, S. M. Qualificação e educaçẫo: reconstruindo nexos e interrelaçôes. In: SAUL, A. M; FREITAS, J. C. Políticas públicas de qualificação: desafios atuais. São Paulo: A+Comunicação, 20.07. p. 9-36.

MIURA, R. K. K. Considerações sobre o Currículo Funcional Natural. Inclusão Escolar: as contribuiçóes da educação especial. São Paulo: Cultura Acadêmica Marília: Fundepe Editora, 2010.

NISKIER, A. Educação, estágio \& trabalho. São Paulo: Integrare, 2006.

ONU. Declaração de Salamanca: princípios, política e prática em educação especial. 1994. Disponível em: http://www.direitoshumanos.usp.br/index.php/Table/Acervo/. Acesso em: 26 dez. 2014.

PAIS, J. M. Ganchos, tachos e biscates: jovens, trabalho e futuro. Porto: Ambar, 2005.

POCHMANN, M. O emprego na globalização: a nova divisão internacional do trabalho e os caminhos que o Brasil escolheu. São Paulo: Bomtempo, 2001.

SANTA CATARINA. Secretaria de Estado da Educação, Ciência e Tecnologia. Fundação Catarinense de Educação Especial. Política de educação especial no estado de Santa Catarina. São José: FCEE, 2009.

SILVA, Adriane Giugni da; PALHANO, Eleanor Gomes da Silva. Formação profissional: uma alternativa inclusiva para pessoas com deficiência. Associação Nacional de Pós-Graduação e Pesquisa em Educação. Disponível em <www.anped.org.br/reunioes/28/textos/gt15/gt151566int.rtf> Acesso em dezembro 2015.

TANAKA, E.D.O.; MANZINI, E.J. O que os empregadores pensam sobre o trabalho da pessoa com deficiência. Revista Brasileira de Educaçáo Especial, Marília, v.11, n.2, p.273-294, 2005.

TROTTIER, C. Emergência e constituição do campo de pesquisa sobre a inserçâo profissional. In: DESAULNIERS, Julieta Beatriz Ramos (Org.) Formação \& trabalho \& competência: questôes atuais. Porto Alegre: EDIPUCRS, 1999. p. 133-177.

VALLE, M. H. F. Vivências de pessoas com deficiência mental inseridas no mercado de trabalho. 120 f. Dissertação (Mestrado em Educação) - Setor de Educação, Universidade do Estado do Rio de Janeiro, Rio de Janeiro, 2004.

\section{Notas}

${ }^{1}$ A formação profissional, na sua acepção mais ampla, designa todos os processos educativos que permitam ao indivíduo adquirir e desenvolver conhecimentos teóricos, técnicos e operacionais relacionados à produçăo de bens e serviços, quer esses processos sejam desenvolvidos nas escolas ou nas empresas.. (CATTANI, 2002, p. 128)

${ }^{2}$ Conforme Laranjeira (2002, p. 123), "[...] o fordismo caracterizar-se-ia como prática de gestão na qual se observa a radical separaçáo entre concepção e execuçáo, baseando-se esta no trabalho fragmentado e simplificado, com ciclos operários muito curtos, requerendo pouco tempo para formaçăo e treinamento dos trabalhadores". Segundo Cattani (2002, p. 308), taylorismo é o "Sistema de organização do trabalho, especialmente industrial, baseado na separação das funçōes de concepção e planejamento das funçōes de execução, na fragmentação e na especialização das tarefas, no controle de tempos e movimentos e na remuneração por desempenho".

${ }^{3}$ O currículo funcional teve início na década de 1970, na Universidade de Kansas (USA), e propôs desenvolver habilidades que levassem os alunos a atuarem da melhor forma possível no ambiente, tornando-os mais criativos e independentes. Segundo Le Blanc (1992), o funcional é no sentido de ensinar habilidades que tenham função para a vida atual e futura.

${ }^{4}$ Serviço de Atendimento Educacional Especializado, instituído pela Fundação Catarinense de Educaçăo Especial, com o propósito de proporcionar aos alunos com deficiências atendimento no contra turno da classe comum, objetivando a complementação para o processo de aprendizagem desses alunos. (SANTA CATARINA, 2009) 
${ }^{5} \mathrm{Na}$ colocação individual, a pessoa com deficiência pode necessitar de suportes físicos e/ou pessoal intensivo e constante, que poderão ser retirados gradativamente. A colocaçáo seletiva, por sua vez, desenvolve-se por meio do sistema de equipes móveis que se deslocam para a variedade de locais de trabalho. (ARAÚJO, 2008)

\section{Correspondência}

Valéria Becher Trentin - Universidade do Vale do Itajaí. : R. Uruguai, 458 - Centro, Itajaí - SC. CEP: 88302901.Itajai, Santa Catarina, Brasil.

E-mail: valeriatret@yahoo.com.br

Recebido em 16 de agosto de 2017

Aprovado em 04 de fevereiro de 2018

\section{(9) (1) @}

This work is licensed under a Creative Commons Attribution-NonCommercial 4.0 International (CC BY-NC 4.0) 
